\title{
Unsymmetrical Failure States in a Small Water Power Station
}

\author{
Vaclav Bartos, Anna Kotlanova \\ Department of Electromechanics and Power Electronics \\ University of West Bohemia in Pilsen, Czech Republic \\ phone: +420 377634 451, fax: +420377634002, e-mail: bartos@kev.zcu.cz, kotlanov@kev.zcu.cz
}

\begin{abstract}
The paper discusses failure states of a small water power station system with an asynchronous generator with capacity compensation. The failures occur during the disconnection of one or two phases from the involved transmission line. The study demonstrates the undesirable voltage changes and the current overloads in various phases.
\end{abstract}

\section{Key words}

Renewable resources of energy, mathematical model, asynchronous machine, failure states, compensative capacitors.

\section{Introduction}

The rapid utilization of fossil-fuel resources and the global movement for clean environments have accelerated the research and development of energy systems using renewable energy sources such as water or wind. The induction generator is discussed as a very suitable machine for this type of applications due to its low cost, simplicity, ruggedness, brushless rotor, ease of maintenance, etc. The induction generator is a three-phase induction machine working either in cooperation with the network or, in case of the self-exciting induction generator (SEIG), with an external capacitor battery, connected across its terminals. The battery provides the magnetizing reactive power that is necessary to establish the air-gap flux. Its shaft is driven by a prime mover.

The paper presents a mathematical model of a small water power station, which supplies the local consumption area and which is connected to the grid. The model can be used for a system working as an independent source of energy as well. In such a case, the system is disconnected from the network. This model is suitable for the design and optimization of the fed condenser battery, so that the value of the power factor corresponds with the Power Company requirements.

\section{Description of the modeled system}

The paper discusses one of the types of failure of the asynchronous generator connected to the grid and provided with the capacity compensation. The mentioned failure occurs during the disconnection of one phase from the in- volved transmission line. The study discusses an actual occurrence at a small water power station in Slovenia and demonstrates the possibility of an undesirable voltage change in the disconnected phase as well as the current overloads in the remaining phases.

The mathematical model of the system consists of an asynchronous generator, compensative battery, transmission line, local consumption network, and the grid. The model is based on the circuit model (Fig. 1) and for the mathematical description uses the nonlinear differential equations.

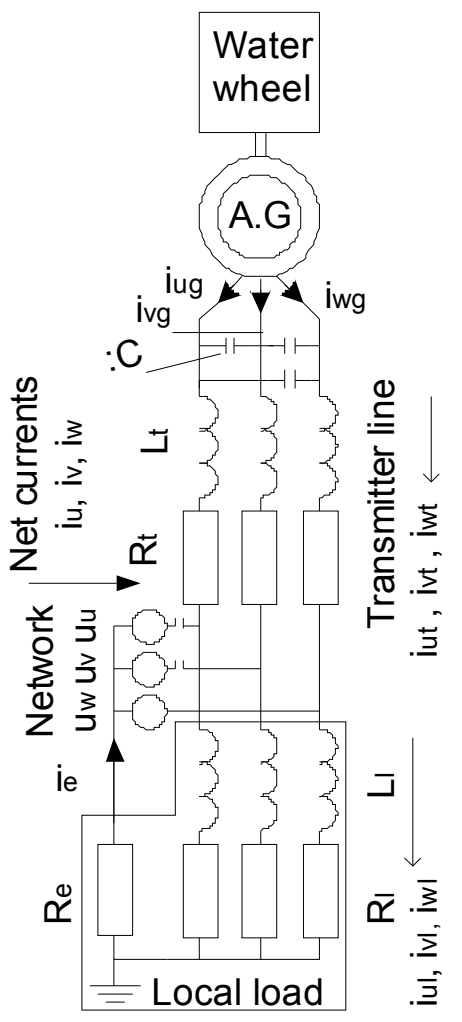

Fig. 1. Circuit diagram of the modeled system

The presented model is a 3-phase model in the reference frame transferred into the stator. Saturation of the magnetic circuit is respected. The system of nonlinear differential voltage equations is completed by torque and mo- 
tion equations. The DYNAST software was used to solve the system.

\section{Mathematical model}

The system of differential equations describing the effect mentioned above is as follows:

Voltage equations for loops

$$
\begin{aligned}
& \mathrm{u}_{\mathrm{u}}=\mathrm{R}_{\mathrm{tu}} \mathrm{i}_{\mathrm{u}}+\mathrm{R}_{\mathrm{l}} \mathrm{i}_{\mathrm{ul}}+\mathrm{L}_{1} \frac{\mathrm{di}_{\mathrm{ul}}}{\mathrm{dt}}+\mathrm{R}_{\mathrm{e}}^{\mathrm{i}_{\mathrm{e}}} \\
& \mathrm{u}_{\mathrm{v}}=\mathrm{R}_{\mathrm{tv}} \mathrm{i}_{\mathrm{v}}+\mathrm{R}_{\mathrm{l}} \mathrm{i}_{\mathrm{vl}}+\mathrm{L}_{1} \frac{\mathrm{di}_{\mathrm{vl}}}{\mathrm{dt}}+\mathrm{R}_{\mathrm{e}} \mathrm{i}_{\mathrm{e}} \\
& \mathrm{u}_{\mathrm{w}}=\mathrm{R}_{1} \mathrm{i}_{\mathrm{wl}}+\mathrm{L}_{1} \frac{\mathrm{di} \mathrm{wl}_{\mathrm{wl}}}{\mathrm{dt}}+\mathrm{R}_{\mathrm{e}} \mathrm{i}_{\mathrm{e}}
\end{aligned}
$$

$u_{u}-u_{v}=R_{t u} i_{u}-R_{t}\left(i_{u t}-i_{v t}\right)-L_{\sigma} \frac{d}{d t}\left(i_{u t}-i_{v t}\right)+u_{\text {cuv }}$

$\mathrm{u}_{v}-\mathrm{u}_{\mathrm{w}}=\mathrm{R}_{\mathrm{tv}} \mathrm{i}_{\mathrm{v}}-\mathrm{R}_{\mathrm{t}}\left(\mathrm{i}_{\mathrm{vt}}-\mathrm{i}_{\mathrm{wt}}\right)-\mathrm{L}_{\sigma} \frac{\mathrm{d}}{\mathrm{dt}}\left(\mathrm{i}_{\mathrm{vt}}-\mathrm{i}_{\mathrm{wt}}\right)+\mathrm{u}_{\mathrm{cvw}}$ $u_{w}-u_{u}=-R_{t u} i_{u}-R_{t}\left(i_{w t}-i_{u t}\right)-L_{\sigma} \frac{d}{d t}\left(i_{w t}-i_{u t}\right)+u_{c w u}$

When $\mathrm{R}_{\mathrm{tu}}, \mathrm{R}_{\mathrm{tv}}$ are models of breakers. $\mathrm{R}_{\mathrm{tu}}, \mathrm{R}_{\mathrm{tv}} \rightarrow 0$ before and $\mathrm{R}_{\mathrm{tu}}, \mathrm{R}_{\mathrm{tv}} \rightarrow \infty$ after the failure.

For the currents in the nodes it can be written

$$
\begin{array}{r}
\mathrm{i}_{\mathrm{ul}}+\mathrm{i}_{\mathrm{vl}}+\mathrm{i}_{\mathrm{wl}}-\mathrm{i}_{\mathrm{e}}=0 \\
\mathrm{i}_{\mathrm{u}}+\mathrm{i}_{\mathrm{ut}}-\mathrm{i}_{\mathrm{ul}}=0 \\
\mathrm{i}_{\mathrm{v}}+\mathrm{i}_{\mathrm{vt}}-\mathrm{i}_{\mathrm{vl}}=0 \\
\mathrm{i}_{\mathrm{w}}+\mathrm{i}_{\mathrm{wt}}-\mathrm{i}_{\mathrm{wl}}=0
\end{array}
$$

$$
\begin{array}{r}
\mathrm{i}_{\mathrm{ul}}+\mathrm{i}_{\mathrm{vl}}+\mathrm{i}_{\mathrm{wl}}-\mathrm{i}_{\mathrm{e}}=0 \\
\mathrm{i}_{\mathrm{u}}+\mathrm{i}_{\mathrm{ut}}-\mathrm{i}_{\mathrm{ul}}=0 \\
\mathrm{i}_{\mathrm{v}}+\mathrm{i}_{\mathrm{vt}}-\mathrm{i}_{\mathrm{vl}}=0 \\
\mathrm{i}_{\mathrm{w}}+\mathrm{i}_{\mathrm{wt}}-\mathrm{i}_{\mathrm{wl}}=0
\end{array}
$$

and also

$$
\text { ) }
$$

$$
i_{u v}=C \frac{d u_{c u v}}{d t}, i_{v w}=C \frac{d u_{c v w}}{d t}, i_{w u}=C \frac{d u_{c w u}}{d t}
$$

The equations of the asynchronous generator's stator and rotor in the matrix form are

$$
\begin{aligned}
& {\left[\mathbf{u}_{\mathrm{sg}}\right]=\left[\mathbf{R}_{\mathrm{sg}}\right] \cdot\left[\mathbf{i}_{\mathrm{sg}}\right]+\underset{\mathrm{dt}}{\stackrel{\mathrm{d}}{\Psi}}\left[\begin{array}{l}
\mathrm{sg}
\end{array}\right]} \\
& {[0]=\left[\mathbf{R}_{\mathrm{rg}}\right] \cdot\left[\mathbf{i}_{\mathrm{rg}}\right]+\underset{\mathrm{dt}}{\boldsymbol{\Psi}}\left[\begin{array}{l}
\mathrm{rg}
\end{array}\right]}
\end{aligned}
$$

where

$$
\left[\mathbf{R}_{\mathrm{sg}}\right],\left[\mathbf{R}_{\mathbf{r g}}\right]
$$

are diagonal matrixes of stator and rotor resistances.

The relation for linkage fluxes can be presented in a short form with the help of a matrix

$$
\begin{aligned}
& {\left[\Psi_{\mathrm{sg}}\right]=\left[\mathbf{L}_{\mathbf{s}}\right] \cdot\left[\mathbf{i}_{\mathrm{sg}}\right]+\left[\mathbf{L}_{\mathrm{sr}}\right] \cdot\left[\mathbf{i}_{\mathbf{r g}}\right]} \\
& {\left[\mathbf{\Psi}_{\mathbf{r g}}\right]=\left[\mathbf{L}_{\mathbf{s r}}\right]^{\mathbf{T}} \cdot\left[\mathbf{i}_{\mathbf{s g}}\right]+\left[\mathbf{L}_{\mathbf{r}}\right] \cdot\left[\mathbf{i}_{\mathbf{r g}}\right]}
\end{aligned}
$$

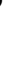

when the matrixes of inductances are

$$
\begin{aligned}
& {\left[\mathbf{L}_{\mathrm{s}}\right]=\left[\begin{array}{ccc}
\mathrm{L}_{\mathrm{s}} & -\mathrm{M}_{\mathrm{s}} & -\mathrm{M}_{\mathrm{s}} \\
-\mathrm{M}_{\mathrm{s}} & \mathrm{L}_{\mathrm{s}} & -\mathrm{M}_{\mathrm{s}} \\
-\mathrm{M}_{\mathrm{s}} & -\mathrm{M}_{\mathrm{s}} & \mathrm{L}_{\mathrm{s}}
\end{array}\right],} \\
& {\left[\mathbf{L}_{\mathrm{r}}\right]=\left[\begin{array}{ccc}
\mathrm{L}_{\mathrm{r}} & -\mathrm{M}_{\mathrm{r}} & -\mathrm{M}_{\mathrm{r}} \\
-\mathrm{M}_{\mathrm{r}} & \mathrm{L}_{\mathrm{r}} & -\mathrm{M}_{\mathrm{r}} \\
-\mathrm{M}_{\mathrm{r}} & -\mathrm{M}_{\mathrm{r}} & \mathrm{L}_{\mathrm{r}}
\end{array}\right]}
\end{aligned}
$$

$\left[\mathbf{L}_{\mathbf{s r}}\right]=\left[\begin{array}{ccc}\mathrm{M} \cos \vartheta & \mathrm{M} \cos (\vartheta+\alpha) & \mathrm{M} \cos (\vartheta-\alpha) \\ \mathrm{M} \cos (\vartheta-\alpha) & \mathrm{M} \cos \vartheta & \mathrm{M} \cos (\vartheta+\alpha) \\ \mathrm{M} \cos (\vartheta+\alpha) & \mathrm{M} \cos (\vartheta-\alpha) & \mathrm{M} \cos \vartheta\end{array}\right]$

$$
\alpha=2 \pi / 3
$$

Due to the configuration of the circuits (see Fig. 1), it is possible to determine the voltages across the condensers as follows:

Relations hold

$$
\begin{aligned}
& u_{\mathrm{cuv}}=\mathrm{u}_{\mathrm{ug}}-\mathrm{u}_{\mathrm{vg}} \\
& \mathrm{u}_{\mathrm{cvw}}=\mathrm{u}_{\mathrm{vg}}-\mathrm{u}_{\mathrm{wg}} \\
& \mathrm{u}_{\mathrm{cwu}}=\mathrm{u}_{\mathrm{wg}}-\mathrm{u}_{\mathrm{ug}}
\end{aligned}
$$

The whole equation system is completed by an equation for the internal electromagnetic torque deduced with the help of a two-phase transformation

$$
\mathrm{T}_{\mathrm{i}}=\Psi_{\mathrm{d}} \mathrm{i}_{\mathrm{q}}-\Psi_{\mathrm{q}} \mathrm{i}_{\mathrm{d}}
$$


and by the motion equation

$$
\mathrm{T}_{\mathrm{i}}-\mathrm{T}_{\mathrm{wv}}=\mathrm{J} \frac{\mathrm{d} \omega}{\mathrm{dt}}
$$

\section{Description of the failure states}

Based on the mathematical formulations mentioned in the previous chapter, a computer model has been created. The disconnection of the phase is modeled by a time-variable resistance, designated as $\mathrm{R}_{\mathrm{ta}}(\mathrm{t})$ in the phase $\mathrm{a}$. The value of this resistance increases by several place values during the given time interval. The moment of the phase disconnection has been set as the instant when the current $\mathrm{I}_{\mathrm{a}}$ passes through zero.

\section{A. Disconnection of one phase; $\cos \varphi=0,98, C=240 \mu F$}

The presented mathematical model simulates connecting a machine running in a constant speed to the transmission line. After the transient phenomenon caused by this connection has been stabilized, one phase gets disconnected with the help of the previously mentioned pulse function, and the modeled failure is executed.

The model was created for an asynchronous machine with the parameters of $30 \mathrm{~kW}, 400 \mathrm{~V}, 58 \mathrm{~A}$. The load before the failure was $18 \%$ of the nominal value, compensated to $\cos \varphi=0,98$ by a compensative capacity $\mathrm{C}=240 \mu \mathrm{F}$. Besides the voltage and current in the disconnected phase, the torque, the speed, and currents in the stator were monitored. The results of the solution are presented in the following figures:

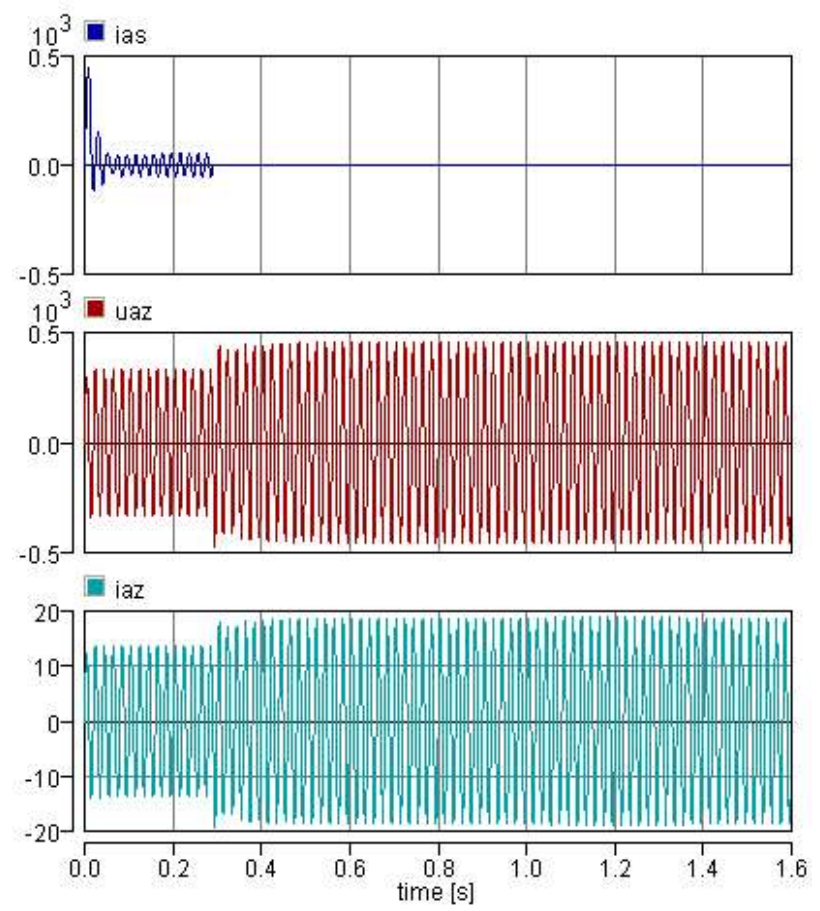

Fig. 2. Current of the disconnected phase, current and voltage across the load impedance
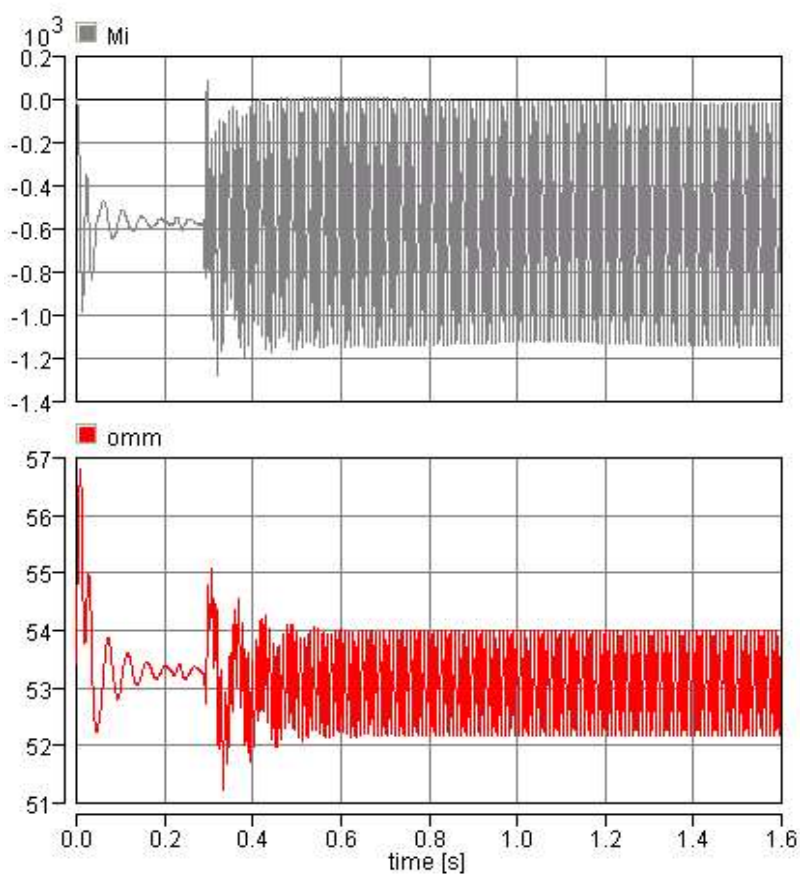

Fig.3 Torque and speed of the asynchronous machine

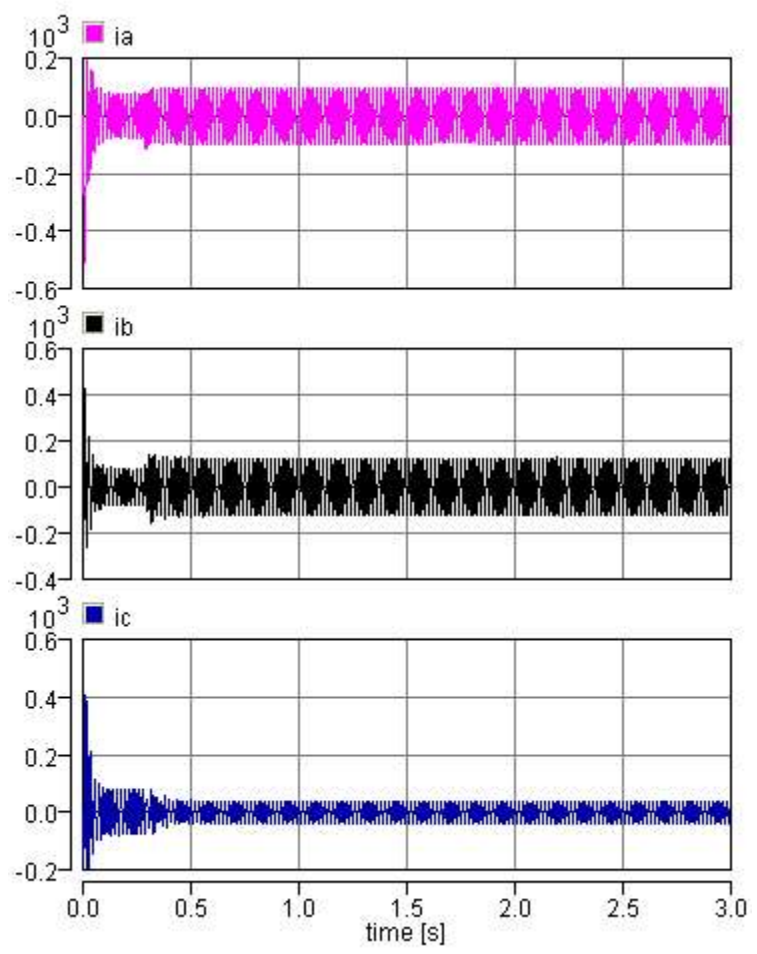

Fig. 4. Stator currents 
The parameters of the modeled machine are the same as in the previous failure state.

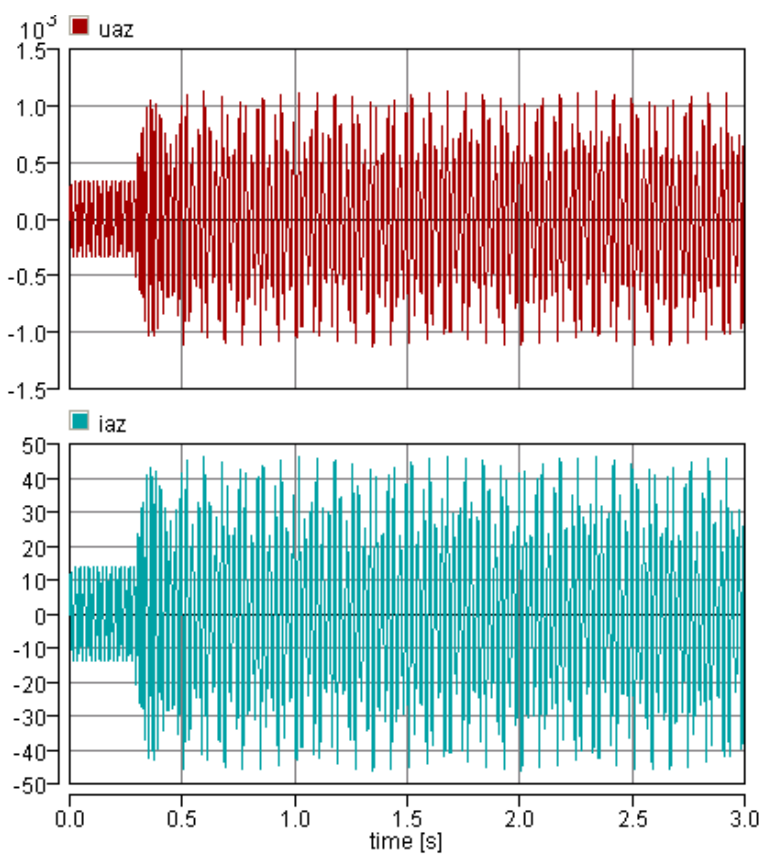

Fig. 5. Current and voltage across the load impedance

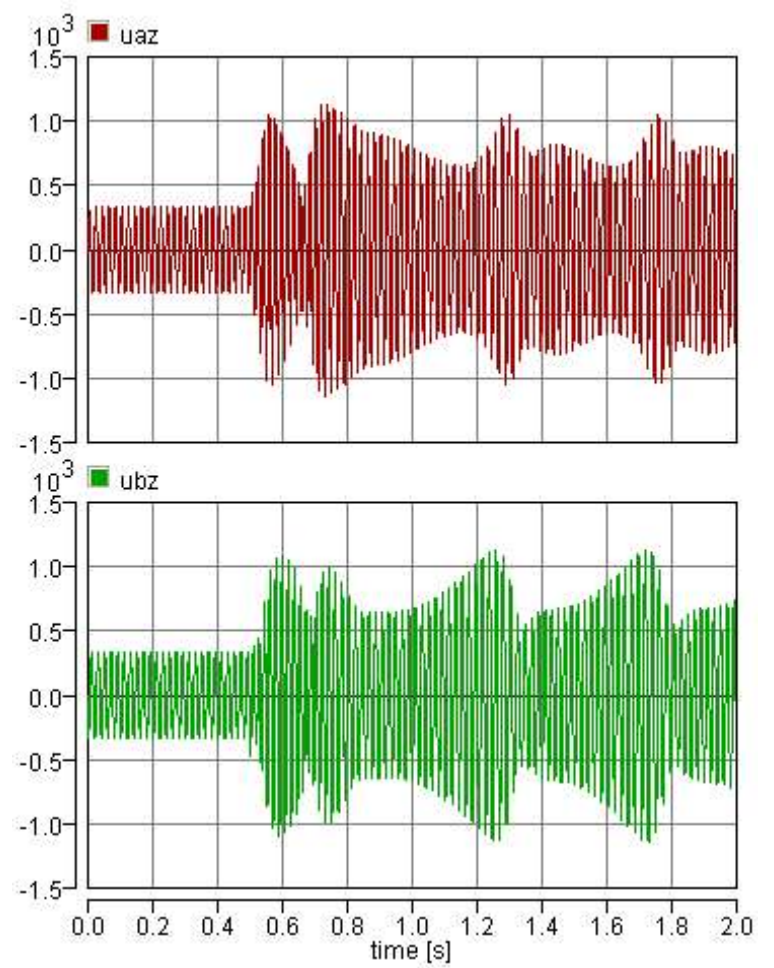

Fig. 6. Voltages across the load impedance of the disconnected phases
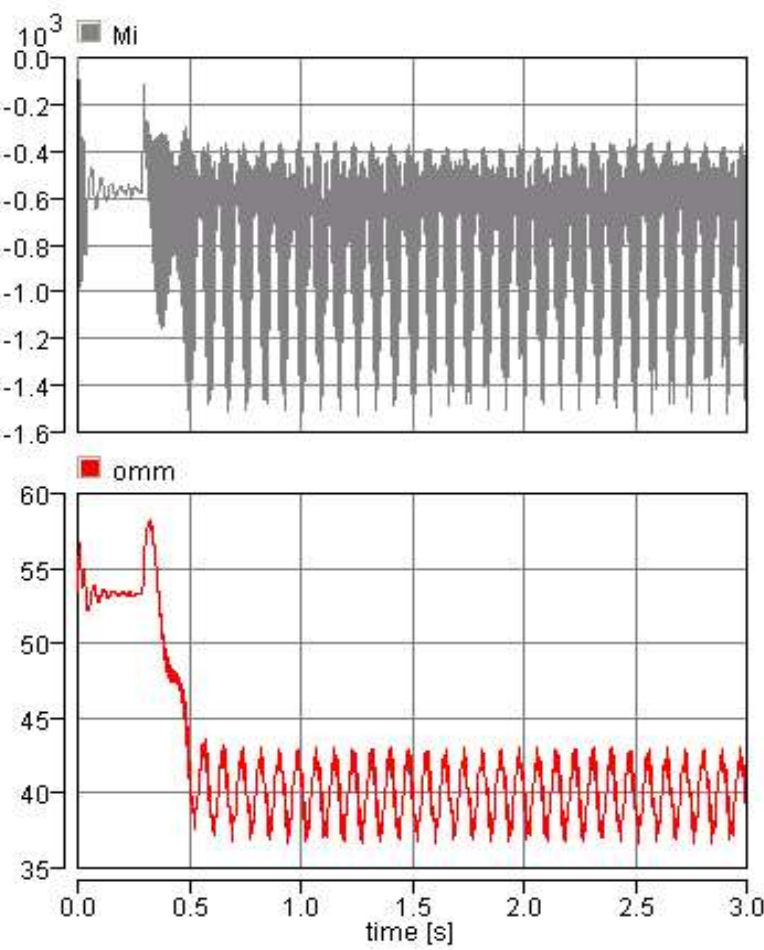

Fig. 7. Torque and speed of the asynchronous machine

C. Disconnection of two phases; $\cos \varphi=0,95, C=175$ $\mu F$

The failure state is identical to the previous one, only the compensative capacity is different, $\mathrm{C}=175 \mu \mathrm{F}$, and the load has a purely ohmic character $\mathrm{R}_{1}=240 \Omega$

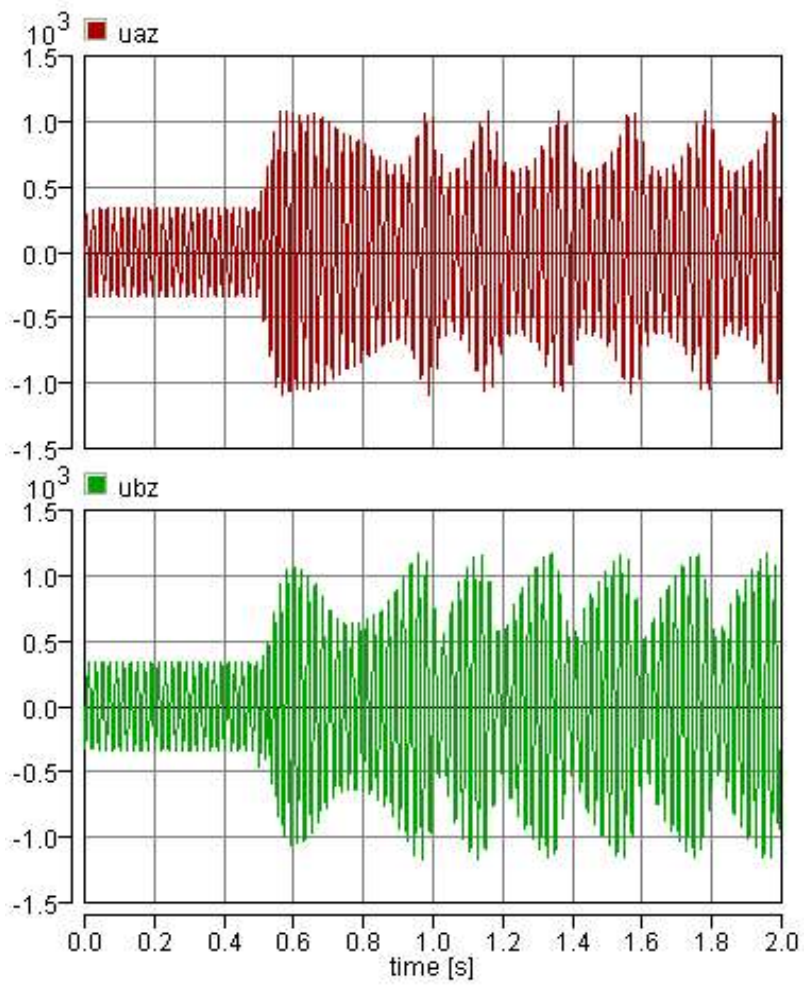

Fig. 8. Voltages across the load impedance of the disconnected phases 


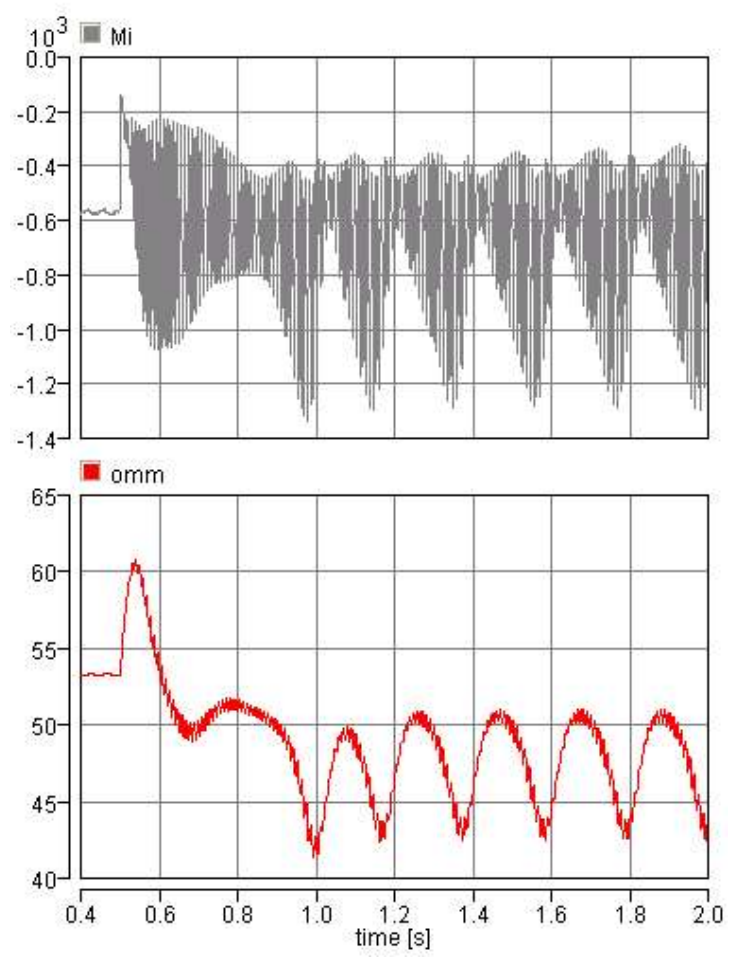

Fig. 9. Torque and speed of the asynchronous machine

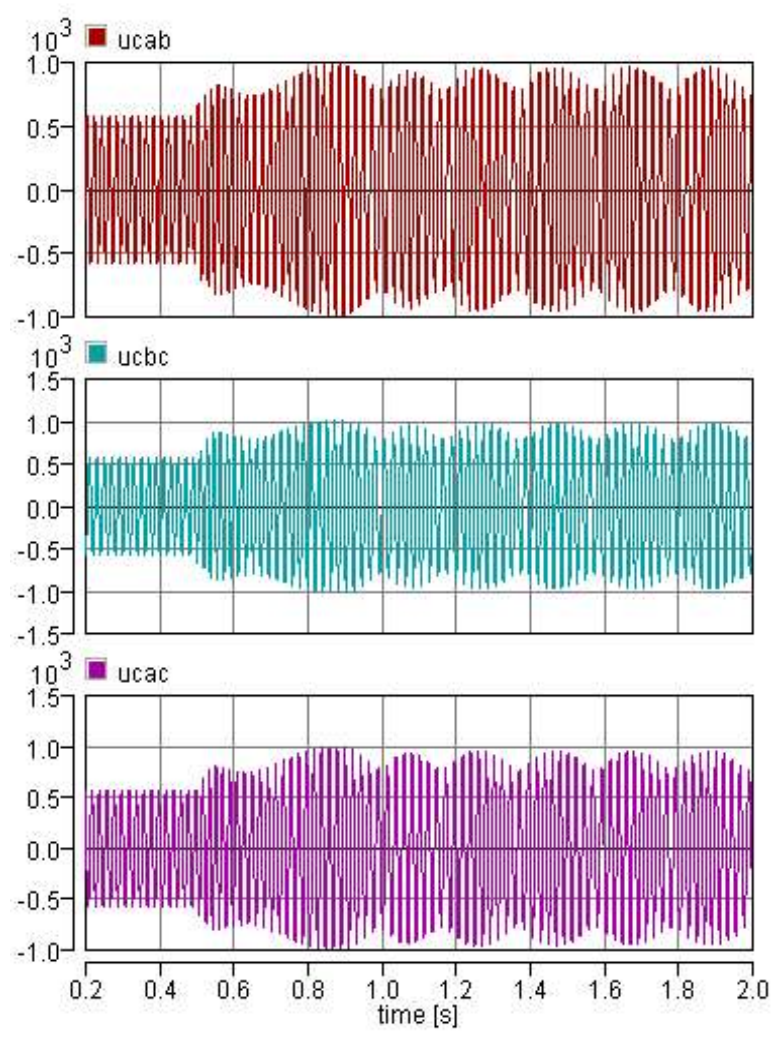

Fig. 10. Voltages across compensative capacitors

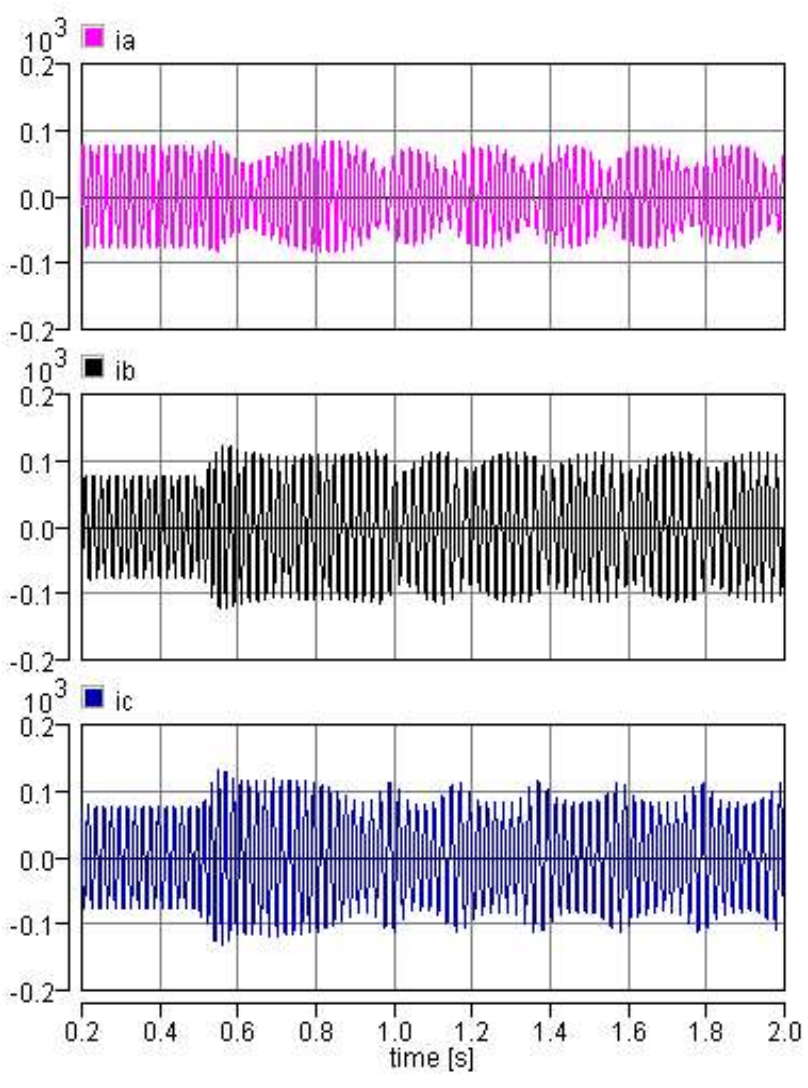

Fig. 11 Stator currents

\section{Conclusion}

The presented results of a simulation of two unsymmetrical failures demonstrate certain hazards in the operation of a small water power station system with an asynchronous generator. In case of an island mode in unsymmetrical failure states, inadmissible voltage changes are involved. These changes (both over-voltage and undervoltage) can jeopardize the connected apparatuses. The values and characteristics of the voltage changes depend on the relation between the power of the generator and the degree and character of consumption in the disconnected phases. Their elimination is feasible with the help of a properly designed protective system, which would for instance register an unsymmetrical regime, and upon its appearance disconnect the generator and the power factor capacitors at the same time. Another option how to eliminate the undesirable over-voltage is to reduce the capacity of the power factor capacitors. However, this method causes a power factor drop. The Power Distribution Companies require a specific value of the power factor (in the Czech Republic it is $\cos \varphi=0,95$ ). The results of mathematical modeling indicate that the solution to this problem consists in reducing the power factor to approximately $\cos \varphi=0,9$.

The above considerations are valid not only for the presented small water power station but, in general, for all sources of energy using asynchronous generators with capacitive compensation, provided their performance corresponds with the required output of the supplied area. 


\section{Nomenclature}

$\mathrm{i}_{\text {ug,vg,wg }} \quad$ generator stator phase currents

[i $\left.\mathbf{i}_{\mathrm{sg}}\right]$ matrix of the generator stator phase currents

[i $\mathbf{i}_{\text {rg }}$ matrix of the generator rotor phase currents

$\mathrm{i}_{\mathrm{uv}, \mathrm{vw}, \mathrm{wu}} \quad$ power factor capacitor currents

$\mathrm{i}_{\mathrm{e}} \quad$ neutral earthing current

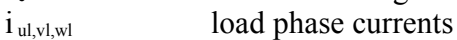

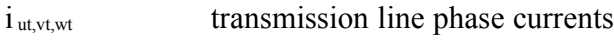

C power factor capacitors

$\left[\mathbf{L}_{s}\right] \quad$ matrix of the self-inductance of the generator stator phase

$\left[\mathbf{L}_{r}\right] \quad$ matrix of the self-inductance of the generator rotor phase

$\left[\mathbf{L}_{\mathrm{sr}}\right] \quad$ matrix of the mutual inductance

$\mathrm{L}_{1} \quad$ load inductance

$\mathrm{L}_{\mathrm{t}} \quad$ transmission line inductance

M mutual inductance between corresponding stator and rotor phases

$\mathrm{M}_{\mathrm{s}} \quad$ mutual inductance between generator stator phases

$\mathrm{M}_{\mathrm{r}} \quad$ mutual inductance between generator rotor phases

$\mathrm{M}_{\mathrm{t}} \quad$ mutual inductance between transmission line phases

$\mathrm{R}_{\text {sg }} \quad$ generator stator winding resistances

$\mathrm{R}_{\mathrm{rg}} \quad$ generator rotor winding resistances

$\mathrm{R}_{\mathrm{e}} \quad$ neutral earth resistance

$\mathrm{R}_{\mathrm{t}} \quad$ transmission line resistance

$\mathrm{R}_{\text {tu,tv }}(\mathrm{t}) \quad$ resistance for modeling of the phase disconnection

$\mathrm{R}_{1} \quad$ load resistance

$\mathrm{U}_{\mathrm{u}, \mathrm{v}, \mathrm{w}} \quad$ transmission line phase voltages

$\mathrm{U}_{\text {ug,vg,wg } \quad \text { generator phase voltages }}$

$\Psi_{\text {sg }} \quad$ generator stator linkage fluxes

$\Psi_{\text {sr }} \quad$ generator rotor linkage fluxes

\section{References}

1] Adkins B., Harley R. G.: The General Theory of Alternating Current Machines, Chappman and Hall, London 1975

[2] Bartos V., Kotlanova A.: Model of Unsymmetrical Failure States of an Asynchronous Generator Research report, West Bohemia University, Pilsen 1994

[3] Bartos V., Kotlanova A.: Magnetic Saturation in Threephase Asynchronous Machine Model, Acta Technica CSAV 42, 455-464

[4] Krause P.,C., Wasynczuk: Electromechanical Motion Devices, McGraw-Hill Book Company 1989 , ISBN 0-07-035524-X

[5] Kovacs K.P., Racz I.: Transiente Vorgange in Wechselstrom-maschinen, Budapest 1959

\section{Acknowledgement}

This work has been supported by the Grant Agency of the Czech Republic under the grant No 102/03/0046 and Strategic Research Project No MSM 232200008. 